\title{
CONSTRUCTION, OPERATION AND EVALUATION OF A RAPID-RESPONSE POTENTIOSTAT
}

\author{
Timothy E. Cummings, Mark A. Jensen and PhiluP J. Elving \\ The University of Michigan, Ann Arbor, Michigan, 48109, U.S.A.
}

(Received 12 January 1978; and in final form 12 April 1978)

\begin{abstract}
Factors involved in cunstruction and utilizalion of an inexpensive, rapid-response potentiostat with $50 \mathrm{~mA}$ current capabilities are discussed. The potentiostat can be used with ancillary units, eg function generators, for a variety of rapid perturbation approaches, eg cyclic voltammetry at scan rates to $4000 \mathrm{~V} / \mathrm{s}$ or greater, potential-step chronoamperometry with data acquisition after $40 \mu \mathrm{s}$ or less, pulse polarography at millisecond or shorter discharge times, and phase-selective $a c$ polarography at frequencies to at least $15 \mathrm{kHz}$. Examination of the Fe(III/II) couple reversibility in oxalate media, the adsorption of adenine, and the dimerization of the NAD free radical are described.
\end{abstract}

\section{INTRODUCTION}

Current electronic technology permits very rapid electrochemical perturbation experiments, eg, measurement of heterogeneous rate constants of $10 \mathrm{~cm} / \mathrm{s}$ and bimolecular rate constants of $10^{8} \mathrm{M}^{-1} \mathrm{~s}^{-1}$; available commercial instruments are very expensive. The trend in commercial electrochemical instrumentation toward the multifunctional device generally limits very rapid perturbation capability; thus, for electrochemical studies of rapid kinetics, it is preferable to use a specifically designed instrument which avoids the problems inherent in multipurpose devices.

A potentiostat is described which has the desired capabilities, can be built for less than $\$ 600$, and can be used with available function generator, phase-selective lock-in amplifier, and read-out device, eg, recorder or oscilloscope. The description is primarily intended for persons with little electrochemical instrument design experience and minimal electronics knowledge.

To test the performance of the potentiostat and critical factors in experimental data handling, the response of chemical systems to various perturbation technics was examined.

The $\mathrm{Fe}(\mathrm{III}) / \mathrm{Fe}$ (II) system in aqueous oxalate media is very rapid on mercury [1-4] and was, therefore, chosen. The adsorption of adenine at the solution/electrode interface and the dimerization of the free radical produced on the initial one-electron reduction of $\mathrm{NAD}^{+}$were also examined.

\section{Essential characteristics of potentiostat}

The general characteristics desired in a potentiostat are stability, high speed response, and high voltage and current capabilities. To achieve high speed response, maximum voltage and current capabilities of $\pm 12 \mathrm{~V}$ and $\pm 50 \mathrm{~mA}$ are generally the available limits, which, except for large scale controlled potential electrolyses, are sufficient for all controlled potential technics.

For cyclic voltammetry, the potentiostat must apply to the working electrode a voltage which rapidly changes linearly with time; any time-lag in current amplifier response will result in anomalous peak potential shifts. For ac polarography, significant electronic circuitry phase shifts must be avoided to prevent anomalous phase differences between the applied ac potential and the measured $a c$ current. Potential-step chronoamperometry requires (a) a rapid potential step rise-time, ie, the potential should settle to the new value in $1 \mu$ s or less, and (b) a large current capability for rapidly charging the double layer without the amplifiers' driving to their current or voltage limit, which would increase the time for double layer charging and, hence, the minimum time for data acquisition without background current.

\section{STRUCTURAL CONSIDERATIONS}

The deleterious effect of switches on a potentiostat's response time is a primary reason why multipurpose instruments generally are not satisfactory for studies of rapid reactions. Minimal use of switches limits the number of built-in perturbation technics. The easiest to include is a linear ramp generator for $d c$ polarography and slow linear-scan voltammetry, which is low frequency, so that signal quality is not degraded by the necessary switching network. Other perturbation signals are introduced into the potentiostat by use of external modules connected to the front panel; necessary incoming signal attenuation is achieved via an external voltage divider circuit.

The potentiostat and timing circuits are shown in Figs 1 and 2. Diagrams of the physical panel arrangement, keyed to Figs 1 and 2, are available from the authors.

\section{Instrument organization}

Three major functions must be achieved by the potentiostat: (a) application of the desired $d c$ voltage and voltage perturbation to the cell ; (b) monitoring of the applied voltage: (c) monitoring of the cell current. The total applied voltage, including initial $d c$ potential, linear ramp potential, perturbation signal, and ir compensation voltage, is monitored by the voltage follower; the cell current is monitored by the current amplifier. The controller amplifier must sum all voltage signals and apply the total voltage to the counter 


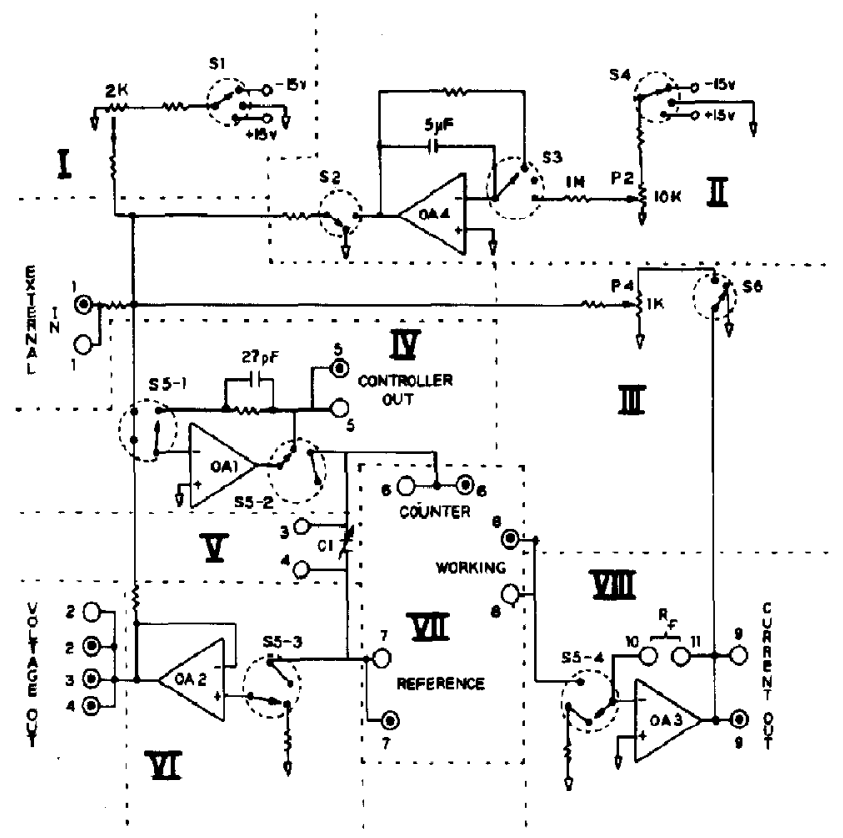

Fig. 1. Potentiostat circuit diagram. Part number symbols: $P$, potentiometer; $S$, switch; OA, operational amplifier; $(\odot)$, BNC receptacle; $(O)$, banana jack. Operational amplifiers 1 to 3 are Teledyne Philbrick Model 1025; operational amplifier 4 is Teledyne Philbrick 1026. The power supply is a Teledyne Philbrick Model 2419,0.5 A, dual power supply. Fixed resistors are $1 \%$ precision; fixed capacitors are $10 \%$ precision. Fixed resistors are $10 \mathrm{k} \Omega$ except where noted. The variable capacitor, $\mathrm{Cl}$, is a 4-30 pF ceramic capacitor. Potentiometers are wirewound. Switch $S$ is multipole; hyphenated number refers to pole number. Switches $S 1$ and $S 4$ are non-shorting type; all other switches are shorting type. Functions shown are $: I$,initial potential circuit; II, linear ramp generator; III, ir compensation circuit; IV, controller amplifier circuit; V, capacitive shunt; VI, voltage follower circuit; VII, cell connections; VIII, current amplifier circuit.

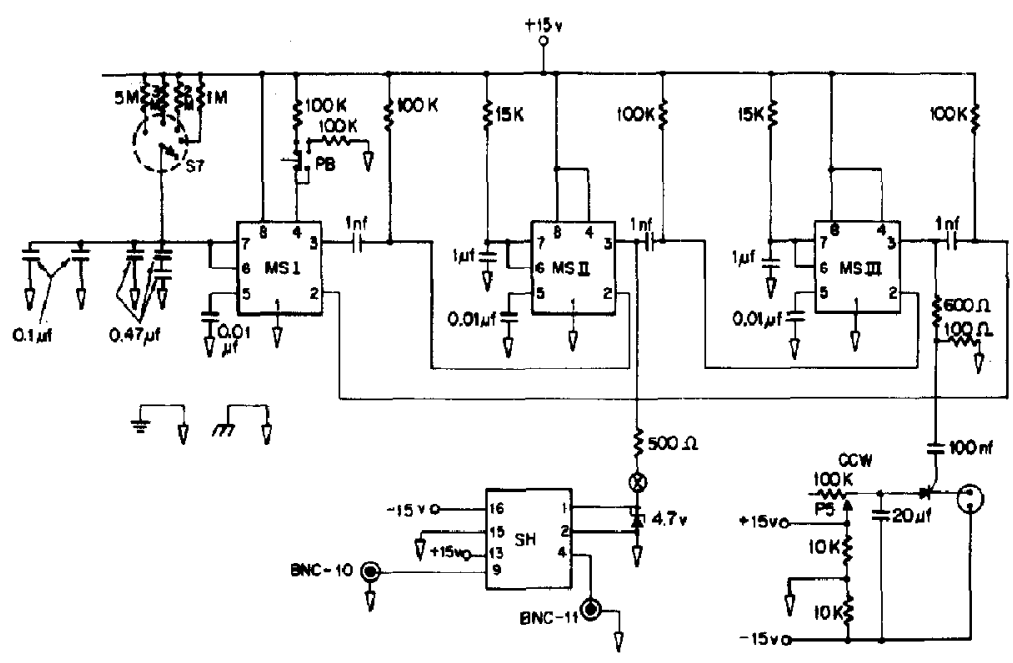

Fig. 2. Potentiostat timing circuit diagram. Part number symbols: MS, monostable multivibrator (Signetics NE 555 timers); SH, sample-and-hold converter (Hybrid Systems SH725LH); S, switch; P, potentiometer. Silicon controlled rectifier is General Electric C11B (2N1774). Power supply for drop-knocker is a Philbrick/Nexus Model 2203, $0.1 \mathrm{~A}$, dual power supply. Resistors are $1 \%$ precision. Capacitors are $10 \%$ precision. Potentiometers are wirewound. All items except the drop-knocker are powered by the Model 2419 power supply of Fig. 1.X preceding connection to SH marks the location for connection of an optional front panel BNC jack permitting access to the 5-V trigger signal from MS II. 
electrode. The potentiostat described permits summation of an initial dc potential, a linear voltage scan, and ir compensation along with a voltage perturbation sigaal; only the latter must be externally applied.

Three-electrode potentiostats operate by maintaining the working electrode at ground and applying a voltage to the counter electrode. Because the electronic circuitry changes the applied voltage polarity, the voltages summed by the controller should have the polarity desired for the working electrode's voltage us the reference electrode; the voltage available at the voltage follower output will be opposite in sign to the working electrode's voltage vs the reference electrode.

\section{Main function switch}

The main function switch should make a vailable a balance mode, standby mode, and cell mode. The balance mode permits balancing each amplifier in an isolated electronic configuration with its appropriate input grounded through a $10 \mathrm{k \Omega}$ resistor. In the cell mode, the potentiostat is connected to the threeelectrode cell configuration. The standby mode is the same as the cell mode except that the working electrode is not connected to the current amplifier, which remains grounded; this permits tuning the capacitive shunt for stable operation without risking electronic oscillation effects on the solution or capillary electrode.

The switch contacts should be large to minimize contact resistance, and high-frequency or transient signal degradation. Use of high quality switches minimizes switch capacitance.

\section{Operational amplifiers}

Operational amplifier selection is critical because of the need for high slew rate, rapid settling, and high current output. Since it is best to employ the same model amplifier in all positions (except the linear ramp generator), the amplifiers must have the high input impedance required for the voltage follower. The amplifiers employed, Philbrick Model 1025, have open-loop characteristics of $500 \mathrm{~V} / \mu$ s slew rate, $75 \mathrm{~ns}$ settling time to $0.1 \%, 50 \mathrm{~mA}$ output current, $10^{12} \Omega$ common mode input impedance, and $5 \mathrm{MHz}$ full output frequency response. Since stable closed-loop configuration can unpredictably alter the characteristics, open-loop characteristics must be considerably superior to the desired potentiostat response.

The linear ramp generator operational amplifier need not respond rapidly or have high current capability. The primary consideration is the high input impedance required to yield a potential scan linear with time, and to permit holding the potential constant for an extended time, ie, ramp-and-hold. The latter requirement can be effected only if the amplifier input bias current is very low (high input impedance), and a high quality capacitor with a large internal resistance is used. The Philbrick Model 1026 amplifier's initial input bias current of $50 \mathrm{pA}$ with common and differential mode input impedance values of $10^{11}$ Ohms are sufficient and allow use of a considerably less costly amplifier.

\section{Physical arrangement}

Circuits carrying high-frequency or transient signals should be compactly grouped to minimize connecting wire length. Specifically, cell connection jacks, ir compensation potentiometer, external function input jacks, capacitive shunt, main function switch and operational amplifiers should be compactly arranged together on or directly behind the front panel. The initial $d c$ potential and linear ramp generator circuits, which carry low frequency signals, may be located away from the operational amplifiers.

Since the input impedance of most read-out devices generally far exceeds the impedance introduced by long segments of hook-up wire, front-panel jacks for voltage follower and current amplifier output mo- nitoring may be located away from the operational amplifiers.

\section{Adjusting capacitive shunts}

Optimum response time - obtained by adjusting parameters which affect the potentiostat's stability for experimental conditions, $e g$, cell geometry, solution composition and perturbation technic - is most easily achieved by using a capacitive shunt between controller output and voltage follower non-inverting input. A small amount of stabilizing capacitance (value depends upon the feedback resistance) may be necessary on the current follower but none should be required on the controller. Because the potentiostat will be stable only within a few pF range about the optimum capacitive shunt value, which is highly dependent upon experimental conditions, a variable air or ceramic capacitive shunt should be a permanent part of the circuit with available external inputs for parallel addition of fixed capacitors as required. Since shunts of very low capacity may occasionally be required, it is unwise to make the variable capacitor externally attachable, as the external connection may easily introduce a few $\mathrm{pF}$. The ceramic capacitor employed has a range of $4-30 \mathrm{pF}$.

\section{Timing circuits}

For experiments employing a dropping mercury electrode (dme), eg, $d c$ and ac polarography, it is frequently useful to control the drop-time by a dropknocker and to employ a sample-and-hold technic for monitoring the current at the end of the drop-life. Figure 2 is a schematic diagram of the drop-knocker and sample-and-hold circuit, for which timing re lationships are shown in Fig. 3. Three Signetics NE 555 timers are wired as monostable multivibrators. Switch S7 is used to select drop-times of approximately $1,2,3$ or $5 \mathrm{~s}$; a potentioneter allowing choice of 0 to $5 \mathrm{~s}$ droptime may be added to the sixth switch position.

The drop-knocker is fired by draining charge from a $20-\mu \mathrm{F}$ capacitor through the solenoid when monostable III is in its high state and the silicon controlled rectifier is open; potentiometer P $\mathbf{5}$ controls the striking force by regulating the capacitor's stored charge. To avoid intermittent loading of the power supply driving the potentiostat, a separate power supply with $0.1-A$ current capability is used for charging the $20-\mu \mathrm{F}$ capacitor.

\section{EXPERIMENTAL}

\section{Chemicals}

Reagent grade $\mathrm{K}_{2} \mathrm{C}_{2} \mathrm{O}_{4} \cdot \mathrm{H}_{2} \mathrm{O}$ (Mallincktodt) and $\mathrm{Fe}_{2}\left(\mathrm{SO}_{4}\right) .6 \mathrm{H}_{2} \mathrm{O}$ (Merck) were used. McIlvaine and 


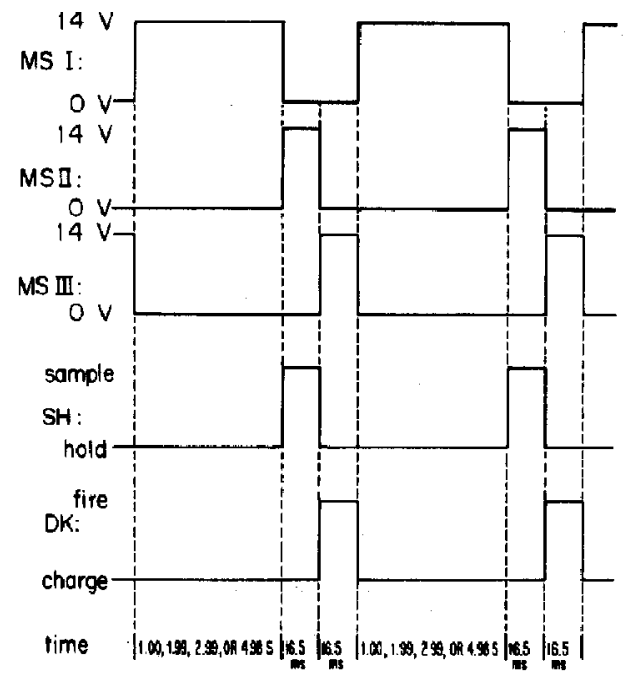

Fig. 3. Timing sequences for controlled drop-timc and current sample-and-hold obtainable from the Fig. 2 circuit.

DK, drop-knocker; other symbols are as in Fig. 2.

carbonate buffers were prepared from reagent grade chemicals. Adenine was obtained from National Biochemicals and $\mathrm{NAD}^{+}$from $\mathrm{P}-\mathrm{L}$ Biochemicals. Mercury for electrodes was chemically purified and distilled.

Solutions were deaerated with water-pumped $\mathrm{N}_{2}$ for $30 \mathrm{~min}$; an $\mathrm{N}_{2}$ atmosphere was maintained in the cell. The $\mathrm{N}_{2}$ was passed through two gas towers containing V(II) solution in $\mathrm{HCl}$ over amalgamated zinc to remove residual $\mathrm{O}_{2}, \mathrm{a} \mathrm{Ca}(\mathrm{OH})_{2}$ tower to remove entrained $\mathrm{HCl}$ and a distilled $\mathrm{H}_{2} \mathrm{O}$ tower to water saturate the $\mathbf{N}_{2}$.

\section{Instrumentation}

The jacketed electrochemical cell (Fig. 4) was thermostatted at $25^{\circ}$. A Luggin capillary was positioned within one drop-diameter of the working electrode. The mean dme $\mathrm{Hg}$ flow-rate was $0.88 \mathrm{mg} / \mathrm{s}$ at open circuit in $1 \mathrm{M} \mathrm{K}_{2} \mathrm{C}_{2} \mathrm{O}_{4}$ at 2.02-s controlled drop-time. The microburet hmde was a Metrohm Model E410 (Brinkmann Instruments).

For $a c$ and $d c$ polarography, a Houston Instruments Model 2000 recorder was used for data readout. For cyclic voltammetry and potential-step chronoamperometry, a Tektronix Model $5103 \mathrm{~N}$ oscilloscope with Type $5 \mathrm{~A} 15 \mathrm{~N}$ and $5 \mathrm{~A} 18 \mathrm{~N}$ voltage-amplifier plug-ins and Type 5B10N time-base was used. A Hewlett-Packard Model 3440A digital voltameter was used to monitor applied dc potentials.

For ac polarography, a Princeton Applied Research Model 121 lock-in amplifier was used. For cyclic voltammetry and potential-step chronoamperometry, a Wavetek Model 114 function generator served as a delay line and a Wavetek Model 112 function generator supplied triangular or square waveforms. The Wavetek 112 supplied both the reference signal and ac modulation voltage for second-harmonic ac polarography.

Reported potentials are $v s$ the sce.

\section{OPERATION AND PERFORMANCF}

The critical factors for fast response are (1) ir compensation, (2) capacitive shunt value, (3) current amplifier feedback resistance and capacitance, and (4) electrochemical cell configuration. The ir compensation should be adjusted to the point at which slight oscillations appear at the voltage follower and current follower outputs. In the standby position, the capacitive shunt is adjusted to the minimum value which stabilizes the potentiostat. The current amplifier feedback resistance, $\boldsymbol{R}_{\boldsymbol{f}}$, should generally be as small as possible; its magnitude will be determined by the highest sensitivity available on the readout device, but a compromise between $R_{f}$ and readout sensitivity may be required to achieve an acceptable signal-to-noise

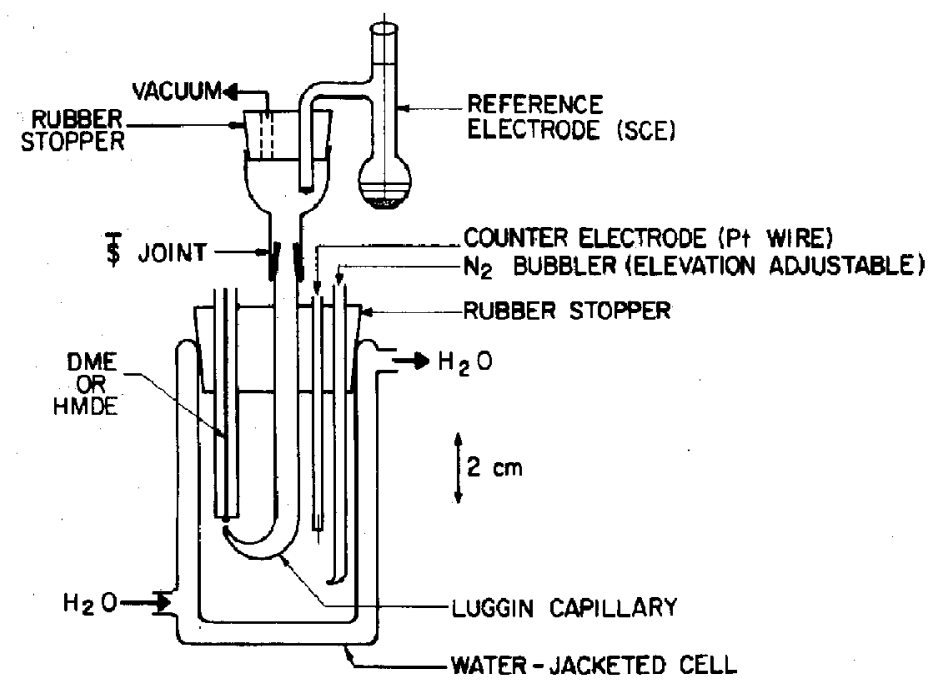

Fig. 4. Single compartment cell for use with Luggin capillary, drawn approximately to scale. 




Fig. 5. Logarithmic analysis of $d c$ polarographic current-potential relationship for $1.59 \mathrm{mM}$ Fe(III) in $1 \mathrm{M}$ $\mathrm{K}_{2} \mathrm{C}_{2} \mathrm{O}_{4}$. Diffusion current $=2.62 \mu \mathrm{A} ; 2.02$-s controlled drop time; $0.88 \mathrm{mg} / \mathrm{s}$ mercury flow rate. Scan rate $=3 \mathrm{mV} / \mathrm{s}$.

ratio.

The counter and working electrodes should be as close together as is feasible; use of a Luggin capillary is imperative (Fig. 4). Low impedance reference electrodes, eg, a large area sce or a platinum or silver wire, cannot always be used. For stable operation, a minimum RC time constant (generally 0.1 to $1 \mu \mathrm{s}$ ) between the capacitive shunt, the solution resistance in the controller feedback loop, and the reference electrode resistance must be achieved. Since solution resistance rarely exceeds $1 \mathrm{k} \Omega$, a high impedance reference electrode is required to avoid use of untenably large capacitive shunts.

\section{DC polarography}

When using a three-compariment cell, dme working electrode, and a large Pt gauze counter electrode, the potentiostat became unstable as the drop fell and restabilized as the new drop grew. Use of the cell shown in Fig. 4 gave no such problems. Because of the small currents generally encountered in dc polarog. raphy, ir compensation was not used.

The Fe(III) wave (Fig. 5) has a log slope of $55.0 \mathrm{mV}$ and $E_{1 / 2}$ of $-0.236 \mathrm{~V}$. The plot's linearity confirms a large heterogeneous rate constant. The diffusion current constant, $I_{\mathrm{d}}=\bar{i}_{\mathrm{d}} / \mathrm{cm}^{2 / 3} t^{1 / 6}$, of 1.36 is smaller than the 1.50 in $0.2 \mathrm{M} \mathrm{K}_{2} \mathrm{C}_{2} \mathrm{O}_{4}$ [5] because of ionic strength effects but in excellent agreement with the 1.37 for oxidation of $\mathrm{Fe}(\mathrm{II})$ in $1 \mathrm{M} \mathrm{K}_{2} \mathrm{C}_{2} \mathrm{O}_{4}[6]$.

\section{Cyclic voltammetry}

No timing synchronization is required for stationary electrode types, $e g$, microburet electrode containing Hg. The signal generator output is connected directly to the external input; manual triggering can be used for single cycle experiments.

When a dme is used with natural drop-time, the perturbation signal must be synchronized to the droplife either manually with a stop-watch or electronically from the charging current spike at the current amplifer output. With controlled drop-times, the MS I or
MS II signal serves as a trigger. The minimum perturbation frequency is $1 / 16.5 \mathrm{~ms}$ or about $60.0 \mathrm{~Hz}$ using MS II as trigger. A delay line may be used if perturbation is desired at times closer than $16.5 \mathrm{~ms}$ to drop-dislodgment, eg, when triggered by the positive going slope of the MS II output, the Wavetek 114 produced a $+5 \mathrm{~V}$ signal which, upon terminating $3.0 \mathrm{~ms}$ before drop-dislodgment, produced a negative going slope used to trigger the triangular waveform (Wavetek 112).

The scan range was set by the attenuation potentiometer on the Wavetek 112 .

Because the voltage follower output equals the sum of the external perturbation signal, the initial potential circuit signal and the ir compensation, while the working electrode voltage does not include the ir compensation term, the potential axis of the read-out device must be driven by the external perturbation signal to avoid distortion by the ir compensation and to reflect the true relative working electrode potential. Since the initial potential circuit signal is not electronically summed to the read-out device potential axis, apparent potentials are offset from the true values by the initial potential circuit signal.

1. Peak potential separation. Typical cyclic voltammograms of $3.03 \mathrm{mM} \mathrm{Fe}$ (III) in $1 \mathrm{M} \mathrm{K}_{2} \mathrm{C}_{2} \mathrm{O}_{4}$, obtained at a microburet hmde, are shown in Fig. 6; ir compensation for $24.5 \Omega$ was used at all scan rates. The oscillations apparent in Fig. 6 for rapid scan rates are probably due to inductive effects of wire-wound potentiometer $\mathrm{P} 4$, the ir compensation potentiometer. The reduction peak-current function and cathodicanodic peak potential separation results in Table 1 indicate that, within experimental uncertainty, the $\mathrm{Fe}$ (III)/Fe(II) system in oxalate media is reversible at scan rates to at least $4000 \mathrm{~V} / \mathrm{s}$; hence, the potentiostat is responding to at least $4000 \mathrm{~V} / \mathrm{s}$ (arbitrarily chosen as the maximum scan rate for testing).

2. Determination of dimerization rates. Dimerization rates, $k_{d}$, of electrochemically generated free radicals 


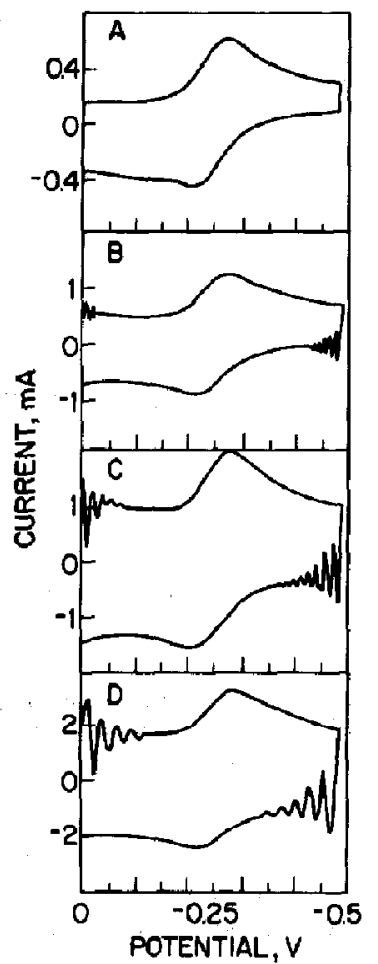

Fig. 6. Cyclic voltammograms of $3.03 \mathrm{mM}$ Fe(III) in $1 \mathrm{M}$ $\mathrm{K}_{2} \mathrm{C}_{2} \mathrm{O}_{4}$ at a hanging mercury drop electrode. Compensation for $24.5 \Omega$ ir loss. Scan rate: $A, 400 \mathrm{~V} / \mathrm{s} ; \mathrm{B}, 1200 \mathrm{~V} / \mathrm{s} ; \mathrm{C}, 2400$

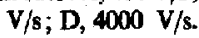

may be determined by cyclic voltammetry at scan rates sufficiently rapid to be competitive with the dimerization under conditions of reversible charge transfer. Determination of $k_{\mathrm{d}}$ is based on correlating the cathodic to anodic peak eurrent ratio as a function of $v$, switching potential and reacting species concentration[7].

For the free radical produced by one-electron reduction of 0.30 or $0.50 \mathrm{mM}$ nicotinamide adenine dinucleotide $\left(\mathrm{NAD}^{+}\right)$at $25^{\circ} \mathrm{C}$ and $\mathrm{pH} 9.1$ in $0.4 \mathrm{M}$ tetraethylammonium chloride with a $0.1 \mathrm{M}$ carbonate buffer, $\mathfrak{a} k_{\mathrm{d}}$ of $(2 \pm 0.3) \times 10^{7} \mathrm{M}^{-1} \mathrm{~s}^{-1}$ was determined (mean and standard deviation for 6 measurements), using $v$ of 250 to $500 \mathrm{~V} / \mathrm{s}[8]$.

Table 1. Cyclic voltammetric behavior of $3.03 \mathrm{mM} \mathrm{Fe(III)} \mathrm{in}$ $1 \mathrm{M} \mathrm{K}_{2} \mathrm{C}_{2} \mathrm{O}_{4} *$

\begin{tabular}{cllll}
\hline$v, \mathrm{~V} / \mathrm{s}$ & $E_{\boldsymbol{w}}, \mathrm{V} \ddagger$ & $\mathrm{E}_{\boldsymbol{p a}}, \mathrm{V} \ddagger$ & $\Delta E_{p}, \mathrm{~V} \S$ & $i_{p} / C^{1 / 2}$ \\
$400 \dagger$ & $-0.288 \dagger$ & $-0.188 \dagger$ & $0.100 \dagger$ & $7.2 \pm 0.2 \dagger$ \\
400 & -0.275 & -0.215 & 0.060 & $7.4 \pm 0.2$ \\
800 & -0.275 & -0.213 & 0.062 & $7.5 \pm 0.3$ \\
1200 & -0.275 & -0.213 & 0.062 & $7.3 \pm 0.2$ \\
2400 & -0.274 & -0.211 & 0.063 & $7.4 \pm 0.2$ \\
4000 & -0.278 & -0.215 & 0.063 & $7.9 \pm 0.9$ \\
\hline
\end{tabular}

- Obtained at an hmde; compensation for $24 \Omega$ resistance; steady-state multiple cycle conditions

+ No ir compensation used.

$\ddagger$ Estimated uncertainty is $\pm 0.003 \mathrm{~V}$.

\& Estimated uncertainty is $\pm 0.004 \mathrm{~V}$.

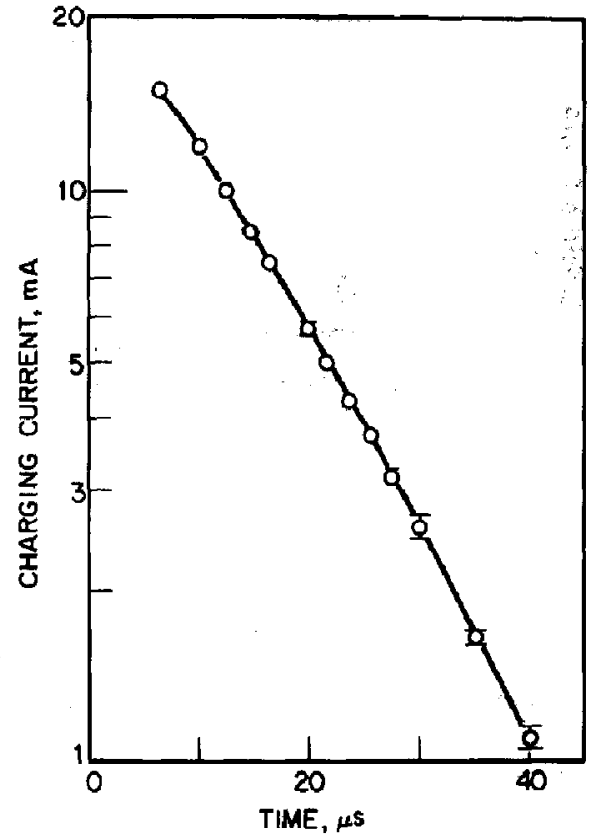

Fig. 7. Variation of the charging current with time for $1 \mathrm{M}$ $\mathrm{K}_{2} \mathrm{C}_{2} \mathrm{O}_{4}$ solution, using potential-step chronosmperometry. Potential step is from -0.16 to $-0.56 \mathrm{~V}$; ir compensation is $49.1 \Omega$; current amplifier feedback resistance and capacitance are $200 \Omega$ and $300 \mathrm{pF}$, respoctively. Maximum time uncertainty is $0.2 \mu \mathrm{s}+0.03 \mathrm{t}$.

\section{Potential-step chronoamperometry}

The Wavetek 112 square waveforms are triggered identically to the cyclic voltammetric case.

The time required for decay of the charging current to a negligible value is the critical factor in response time. Because the total charge required for the double layer is dirsetly proportional to the electrode area and amplifiers' current capability is finite, as small a working electrode as is feasible should be employed. Sphericity effects should not be important for short duration perturbation signals.

The current amplifier feedback resistance, $R_{f}$, is an important factor in determining the double layer charging time, $e g$, if an $R_{f}$ of $1 \mathrm{k} \Omega$ is used on an operational amplifier which voltage-limits at $12 \mathrm{~V}$, only $12 \mathrm{~mA}$ of current can flow before the operational amplifier is voltage-limited, thereby abrogating its $50-$ $\mathrm{mA}$ capability to charge the double layer rapidly.

1. ir compensation. Two factors must be considered in setting the amount of ir compensation: (a) Permitting the current amplifier to voltage-limit is unwise hecause of an operational amplifier's uncertain behaviour during the recovery time after a voltagelimited state. (b) Severe ringing, eg, bursts of current and voltage oscillations similar to those seen in Fig. 6, when ir compensation is employed, can have unknown effects on the concentration profile of an electroactive species.

Potential-step experiments on $1.56 \mathrm{mM}$ Fe(III) in $1 \mathrm{M} \mathrm{K}_{2} \mathrm{C}_{2} \mathrm{O}_{4}$ at a dme showed that, with $R_{f}=0.2 \mathrm{k} \Omega$, the current amplifier was at the point of limiting at $c a$ $12-13 \mathrm{~V}$, when $52.0 \Omega$ of $i r$ compensation was used. A 


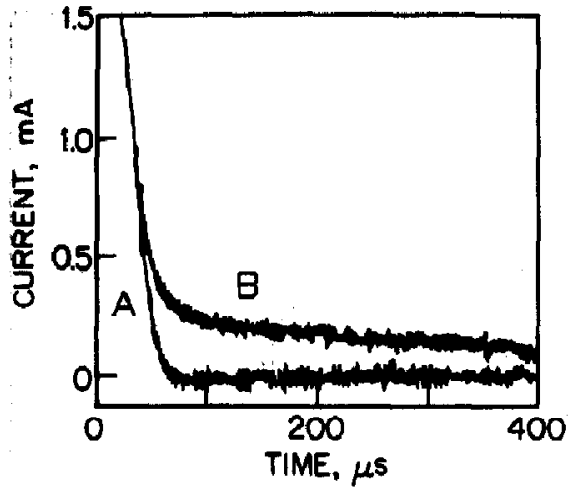

Fig. 8. Current-time behavior on potential-step chronoamperometry. Potential step is from -0.16 to $-0.56 \mathrm{~V}$. A : $1 \mathrm{M}$ $\mathrm{K}_{2} \mathrm{C}_{2} \mathrm{O}_{4} ; 49.1 \Omega$ ir compensation. $\mathrm{B}: 1.56 \mathrm{mM} \mathrm{Fe}$ (III) in $1 \mathrm{M}$ $\mathrm{K}_{2} \mathrm{C}_{2} \mathrm{O}_{4} ; 52.0 \Omega$ ir compensation.

small amount of ringing occurred only during the first 1 to $2 \mu$ s after pulse application; reduction of the ir compensation prolonged the double layer charging time. A plot of log charging current $v$ s time is linear within experimental uncertainty after $15 \mu$ s (Fig. 7) and decays to a value below the peak-to-peak noise within $70 \mu \mathrm{s}$. The initial negative deviation from linearity may be residual effects from the ringing. The current--time variation for background alone and with Fe(III) are shown in Fig. 8. A plot of Faradaic current vs $t^{-1 / 2}$ for Fe(III) (Fig. 9), based on curve B of Fig. 8, is linear, within the $68 \%$ uncertainty bars, as expected for a diffusion-controlled process. The appreciable noise



Fig. 10. Current-time behavior at short times on potentialstep chronoamperometry. Potential step and ir compensation are as in Fig. 8. A : $1 \mathrm{M} \mathrm{K}_{2} \mathrm{C}_{2} \mathrm{O}_{4} . \mathrm{B}: 1.56 \mathrm{mM} \mathrm{Fe}(\mathrm{III})$ in $1 \mathrm{M} \mathrm{K}_{2} \mathrm{C}_{2} \mathrm{O}_{4}$.

in Fig. 8, which is likely due to radio signal pickup, causes the variability in Fig. 9; the initial apparent slight minimum in background curve may be due to an overshoot caused by ringing.

2. Effect of double layer charging. Problems associated with data acquisition during double layer charging are exemplified by Figs 10 and $11, e g$, the Fe(III) and background alone solutions did not require identical ir compensation; it is unclear how this affects the validity of background subtraction. The large peak in Fig. 11 (maximum at ca $20 \mu \mathrm{s}$ ), whose duration is equivalent to the double layer charging



Fig 9. Diffusion-controlled relationship seen for $1.56 \mathrm{mM}$ Fo(III) in $1 \mathrm{M} \mathrm{K}_{2} \mathrm{C}_{2} \mathrm{O}_{4}$ solution on potential-step chronoumperometry : variation of diffusion current $\left(i_{4}\right)$ with time $(t)$. Potential step is from -0.16 to $-0.56 \mathrm{~V}$; tr compensation is $\mathbf{5 2 . 0 \Omega}$; current amplifier parameters are as in Fig. 7. Uncertainty bars represent $68 \%$ confidence interval based on peak noise equal to thrie population standard deviations. Maximum time uncertainty is $1.1 \mu \mathrm{s}+0.03 \mathrm{t}$. 


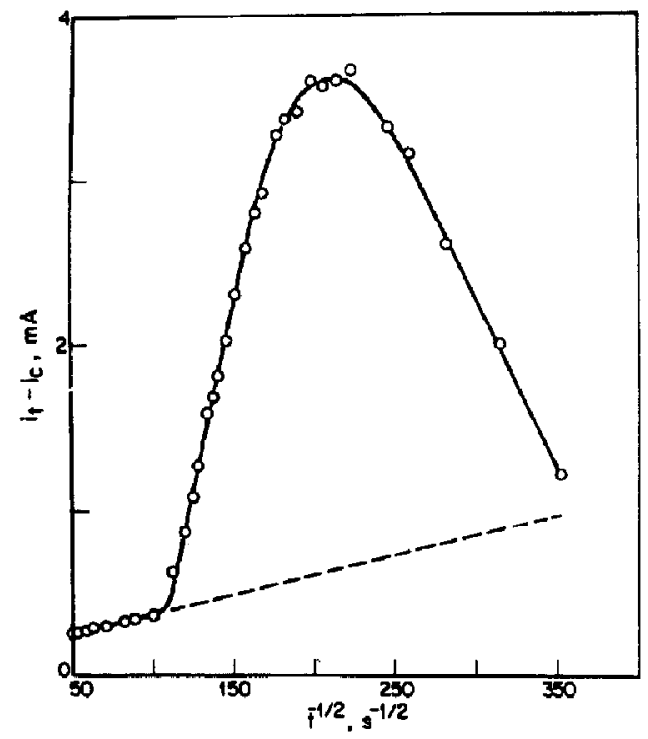

Fig. 11. Current-time (i-t) behavior at short times on potential-step chronoamperometry. Curve represents the difference between curves $B\left(i_{1}\right)$ and $A\left(i_{c}\right)$ in Fig. 10, ie, the difference between the total current for a Fe(III) solution and the charging current for the background solution, extended to $400 \mu \mathrm{s}$.

time, is probably due to different double layer charging rates.

A potential-step experiment at the hmde showed that the double layer could be charged in about $10 \mu \mathrm{s}$ for a small area, low resistance electrode (Fig. 12). A plot of Faradaic current $v^{-1 / 2}$ for Fe(III) (Fig. 13), based on curve B of Fig. 12, is linear after $40 \mu \mathrm{s}$.

Depending on the solution resistance and the electrode resistance and capacitance (hence, area), reliable faradaic measurements can be made at times as short as $40 \mu \mathrm{s}$, which permits determination of heterogeneous rate constants as large as $0.5 \mathrm{~cm} / \mathrm{s}[9]$, first-

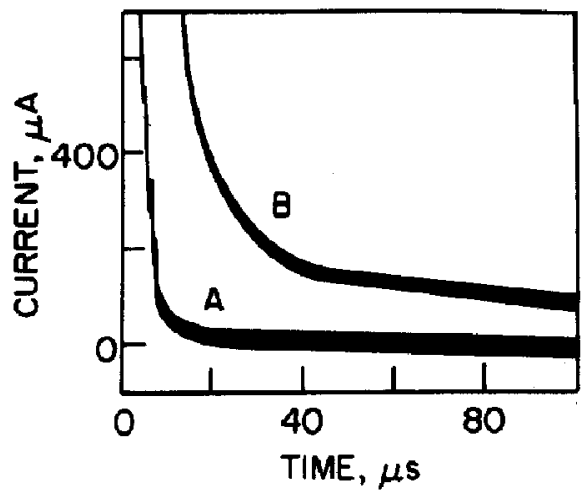

Fig. 12. Current-time behavior on potential-step chronoamperometry at a hmde. Conditions : $3.03 \mathrm{mM}$ Fe(III) in $1 \mathrm{M}$ $\mathrm{K}_{2} \mathrm{C}_{2} \mathrm{O}_{4} ; 11.0 \Omega$ ir compensation. $\mathrm{A}$ : Potential step is from -0.50 to $-0.70 \mathrm{~V}$ (both potentials are on the Fe(III) diffusion plateau). B: Potential step is from -0.10 to $-0.30 \mathrm{~V}$, ie, from a potential before the initiation of $\mathrm{Fe}$ (III) reduction to a potential on Its diffusion plateau. order rate constants of $10^{4}$ to $10^{3} \mathrm{~s}^{-1}$ associated with an ECE mechanism[10], first-order rate constants of $10^{4} \mathrm{~s}^{-1}$ associated with an EC mechanism[11], and dimerization rates of $10^{8} \mathrm{M}^{-1} \mathrm{~s}^{-1}[8,12]$.

\section{Normal pulse polarography}

Use of the potentiostat for NPP has been described [13], but will be summarized here for completeness. The timing circuitry and auxiliary signal generators are those described for potential-step chronoamperometry.

The potentiostat was used to observe the Faradaic and nonFaradaic currents seen for $10 \mu \mathrm{M}$ adenine in $\mathrm{pH} 4.8$ Mcllvaine buffer ( $0.5 \mathrm{M}$ ionic strength) on $d c$ polarography, phase-selective ac polarography, NPP, and rapid scan cyclic voltammetry at the dme and hmde; results were analysed in terms of adenine adsorption, its Faradaic reduction in the adsorbed and unadsorbed states, and coupled chemical reactions[13]. NPP currents, obtained by stepping from the applied potential, $E_{p p}$, to $-1.48 \mathrm{~V}$ after times of 2 or $5 \mathrm{~s}$, are shown in Fig. 14. For background solutions, the charging current due to the pulse decayed to 1 to $2 \mu \mathrm{A}$ within $0.2 \mathrm{~ms}$.

\section{$A C$ polarography}

Because phase-angle measurements are relative to the working electrode ac potential, lock-in amplifier detector adjustments were made using the potentiostat's voltage follower output as the input signal, thereby correcting for any phase shifts due to the controller amplifier. The lock-in frequency trim was adjusted to maximize the in-phase mode detector response; the phase angle was then adjusted to give an out-of-phase (quadrature) mode null signal. These steps insure lock-in amplifier tuning to the applied ac

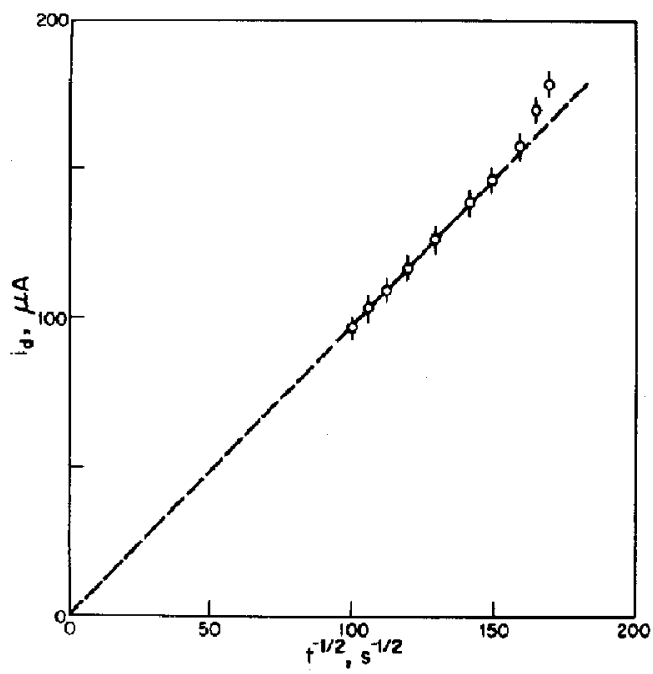

Fig. 13. Diffusion-controlled relationship seen for $3.03 \mathrm{mM}$ $\mathrm{Fe}$ (III) in $1 \mathrm{M} \mathrm{K}_{2} \mathrm{C}_{2} \mathrm{O}_{4}$ solution on potential-step chronoamperometry at a hmde: variation of diflusion current $\left(i_{d}\right)$ with time ( $t$ ). Potential step is from -0.10 to $-0.30 \mathrm{~V}$; ir compensation is $11.0 \Omega$; current amplifier parameters are as in Fig. 7. Uncertainty bars represent best estimate of one standard deviation. Maximum time uncertainty is $0.3 \mu \mathrm{s}$ $+0.03 t$. 


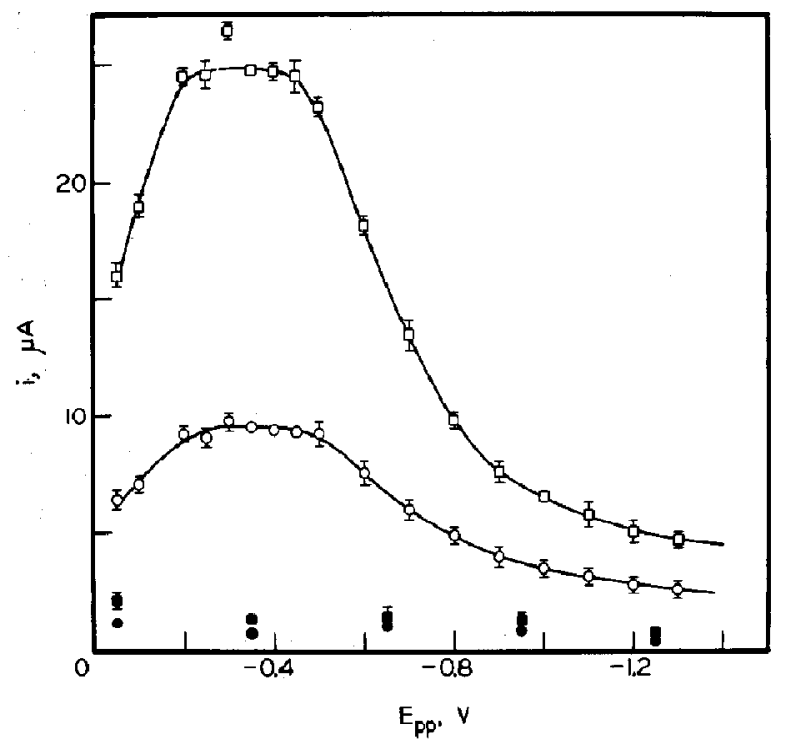

Fig. 14. Currents obtained for $10 \mu \mathrm{M}$ adenine in $\mathrm{pH} 4.8 \mathrm{Mcllvaine}$ buffer ( $(0.5 \mathrm{M}$ ionic strength) on normal pulse polarography on stepping the potential from prepolarization potential noted to $-1.48 \mathrm{~V}$ after prepolarization periods of $2 \mathrm{~s}$ (circles) and $5 \mathrm{~s}$ (squares); the bottom two curves are for the buffer alone. The discharge period was $3 \mathrm{~ms}$; the current measurement period was $25 \mu$ s. Taken from reference 13 with permission.

modulation voltage frequency and definition of this voltage's phase angle as $0^{\circ}$.

Since a $5-\mathrm{mV}$ peak ac modulation voltage was used, adjusting the lock-in gain at the $5-\mathrm{mV}$ setting for fullscale response to the voltage follower output served as an internal correction for any error in setting the modulation voltage amplitude because the ac current is proportional to the $a c$ voltage; thus, a gain setting for full scale response on a $4.9-\mathrm{mV}$ signal amplifies the true applied $a c$ voltage by $2.04 \%$; however, the true ac currents are similarly amplified. The identical alteration of applied ac voltage and resulting ac currents means that the parameters sought, $I(\omega t) / \Delta E$ and $\phi$ will be correct; $I(\omega t)$ is the Faradaic current, $\Delta E$ is the applied ac potential at the $d m e$ interphase, and $\phi$ is the Faradaic current phase angle.

1. Phase relations. It is necessary to insure that the operational amplifiers do not alter the incoming signal phase. Instrumental phase shifts in the controller amplifier-voltage follower loop are easily detected by adjusting the lock-in phase so that the lock-in signal is at $0^{\circ}$. After reference signal connection to the potentiostat, the voltage follower output phase, which should be $0^{\circ}$, is checked in standby and cell-in positions. A phase shift in the standby position indicates the controller and/or voltage follower are not responding at the frequency used or the capacitive shunt is not tuned. A phase shift only in the cell-in position indicates that the capacitive shunt needs retuning under current load conditions or the solution resistance between counter electrode and Luggin capillary is too large, a circumstance likely only in nonaqueous, work. The potentiostat showed no detectable phase shift over the frequency range tested, $600 \mathrm{~Hz}$ to $15 . \mathrm{kHz}$ (artibrarily chosen as the maximum frequency for testing), ie, any phase shift was less than the maximum $\pm 0.2^{\circ}$ uncertainty.

Current amplifier phase shifts are detectable by monitoring the $a c$ capacitive current, $\Delta i_{e}$, frequency dependence at fixed $E_{\mathrm{d} c}$. For frequencies, $f$, as low as $600 \mathrm{~Hz}$, the ir loss in the $a c$ modulation yoltage may be significant. Since a plot of $\Delta i_{c} / \Delta E$ vs $f$ should be linear and since calculation of $\Delta E$ is dependent on the measured phase angle of $\Delta i_{s}$, deviation from linearity, which will be significant by the time anomolous phase shifts reach $1^{\circ}$, will indicate response failure.

2. Examination of $F e(I I I)$ system. Phase-selective ac polarograms for $\mathrm{Fe}$ (III) in $1 \mathrm{M} \mathrm{K}_{2} \mathrm{C}_{2} \mathrm{O}_{4}$ are shown in Figs $15 \mathrm{~A}$ and 15B. Because of ir loss, the ac currents can be compared only after normalization for the $a c$ voltage at the working electrode.

The $\Delta i_{c}$ for $1 \mathrm{M} \mathrm{K}_{2} \mathrm{C}_{2} \mathrm{O}_{4}$, measured at $E_{d c}=$ $-0.245 \mathrm{~V}$ between 0.6 and $15 \mathrm{kHz}$ (Fig. 16), indicate no appreciable phase shift. The arrows at $\omega=\mathbf{9 . 4 2}$ $\times 10^{4} \mathrm{~s}^{-1}$ show the predicted $\Delta i_{c} / \Delta E$ for a current amplifier induced $\pm 1^{\circ}$ shift. At 6 and $9 \mathrm{kHz}$, the lockin amplifier showed a response degradation which may be the source of small negative deviations at these two frequencies.

The linear plot of normalized summit currents for $\mathrm{Fe}$ (III) as a function of $\omega^{1 / 2}$ (Fig. 17) suggests that, up to $15 \mathrm{kHz}$, the $\mathrm{Fe}(1 \mathrm{II})$ reduction is totally, or nearly totally, a reversible, diffusion-controlled process. The phase angles observed at the summit potential, $\phi_{s}$, considered a more sensitive test of reversibility and diffusion control, are generally within the experimental uncertainty of $45^{\circ}$ (Table 2); this is also apparently the situation for $\phi$ at the $d c$ polarographic $E_{1 / 2}$. The $\mathrm{Fe}(\mathrm{III}) / \mathrm{Fe}$ (II) system in $1 \mathrm{M} \mathrm{K} \mathrm{K}_{2} \mathrm{C}_{2} \mathrm{O}_{4}$ has been reported[4] to have a rate constant $\left(k_{t, h}\right)$ of $1.16 \mathrm{~cm} / \mathrm{s}$ and a transfer coefficient $(\alpha)$ of 0.86 , which, at $1500 \mathrm{~Hz}$, should result in a $\phi$ of $43.1^{\circ}$ at an $E_{\mathrm{s}}$ of $-0.245 \mathrm{~V}$. 


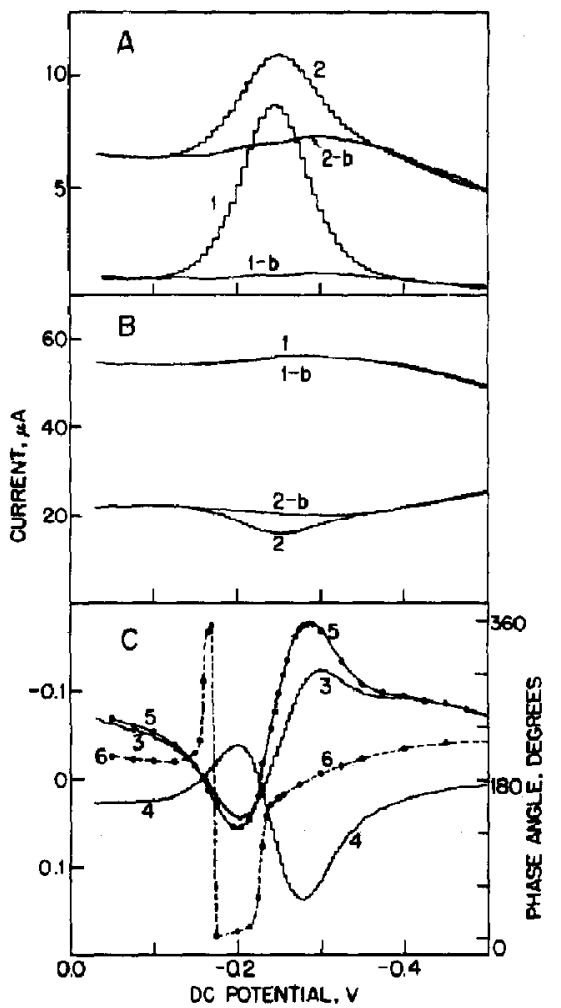

Fig. 15. Phase-selective ac polarography of $1 \mathrm{M} \mathrm{K}_{2} \mathrm{C}_{2} \mathrm{O}_{4}$ solutions. Conditions, unless otherwise noted: drop-time. $2.02 \mathrm{~s}$; mercury flow rate, $0.88 \mathrm{mg} / \mathrm{s}$ : ac modulation voltage, $4.9 \mathrm{mV}$ peak at $600 \mathrm{~Hz}$; scan rate, $4 \mathrm{mV} / \mathrm{s} . \mathrm{A}: 1$ and $\mathrm{l}-\mathrm{b}$, inphase current component; 2 and 2-b, quadrature current component; 1 and $2,1.59 \mathrm{mM}$ Fe(III) added. B : frequency $=15 \mathrm{kHz}$; curves as in panel $A . C$ : second-harmonic behavior; frequency $=1500 \mathrm{~Hz} ; 1.56 \mathrm{mM} F($ III) added; phase-selective second-harmonic signal, 3 is $+47.4^{\circ}$ setting on lock-in and 4 is $+137.4^{\circ}$ setting on lock-in; total second harmonic signal, 5 is current and 6 is phase angle. Data are uncorrected for tr loss effect on modulation voltage and phase angle.

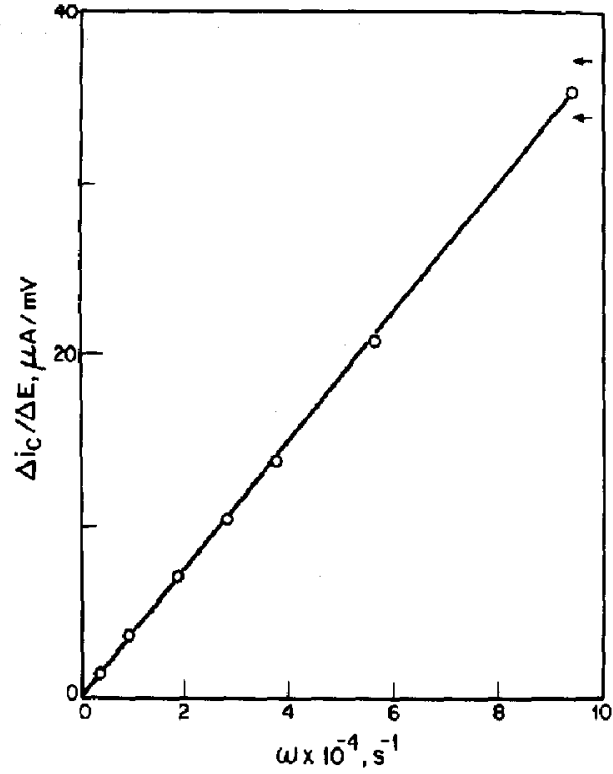

Fig. 16. Variation of ac polarographic charging current functions, $\Delta i_{\varepsilon} / \Delta E$, to frequency, $\omega$ in radians $/ s$, at $E_{\mathrm{dr}}=$ $-0.245 \mathrm{~V}$ for $1 \mathrm{M} \mathrm{K}_{2} \mathrm{C}_{2} \mathrm{O}_{4}$ solution; other conditions are as for Fig. 15.

Phase shifts associated with the lock-in input sensitivity switching circuit were observed to be as large as $1.6^{\circ}, e g$, when the lock-in phase was adjusted so that, at the $5-\mathrm{mV}$ sensitivity, a $5-\mathrm{mV} 1500 \mathrm{~Hz}$ signal was at $0^{\circ}$ with the monitor set on "out * 10", and the input sensitivity was switched to $2-\mathrm{mV}$, the signal was $1.65^{\circ}$ out of phase. Correction of the $1500-\mathrm{Hz} \mathrm{Fe}$ (III) data at the fundamental peak for the $1.65^{\circ}$ phase shift yielded a value for $\phi_{3}$ of $44.6^{\circ}$, in good agreement with the $43.1^{\circ}$ predicted for the published kinetic parameters; because of uncertainty regarding lock-in phase shift reproducibility, no attempt was made to correct $\phi_{r}$ in Table 2.

For phase-selective second-harmonic ac polarog-

Table 2. Ac polarographic Faradaic response of $1.59 \mathrm{mM} \mathrm{Fe}(\mathrm{III})$ in $1 \mathrm{M} \mathrm{K}_{2} \mathrm{C}_{2} \mathrm{O}_{4}{ }^{*}$

\begin{tabular}{|c|c|c|c|c|c|c|c|}
\hline$\underset{\mathrm{kHz}}{f}$ & $\begin{array}{c}\omega \\
10^{-4} s^{-1}\end{array}$ & $\begin{array}{l}\phi_{1 / 2} \dagger \\
\text { degr. }\end{array}$ & $\underset{V}{-E_{s}}$ & $\underset{\mathrm{mV}}{\Delta E_{w a t} \neq}$ & $\begin{array}{c}I_{\Delta}(\omega t) \\
\mu \mathrm{A}\end{array}$ & $\begin{array}{c}I_{s}(\omega t) / \Delta E_{w *} \\
\mu \mathrm{A} / \mathrm{mV}\end{array}$ & $\underset{\text { degr. }}{\phi, \$}$ \\
\hline 0.60 & 0.377 & 45.5 & 0.245 & $4.24(0.04)$ & $8.79(0.13)$ & $2.07(0.04)$ & $46.6(1.3)$ \\
\hline 1.50 & 0.942 & 47.2 & 0.245 & $3.74(0.03)$ & $12.19(0.20)$ & $3.26(0.06)$ & $47.9(1.7)$ \\
\hline 3.00 & 1.89 & 47.5 & 0.245 & $3.14(0.03)$ & $14.51(0.34)$ & $4.62(0.12)$ & $47.2(2.8)$ \\
\hline 4.50 & 2.83 & 49.3 & 0.250 & $2.72(0.03)$ & $15.20(0.52)$ & $5.59(0.20)$ & $50.9(4.0)$ \\
\hline 6.00 & 3.77 & 49.6 & 0245 & $2.40(0.03)$ & $14.93(0.68)$ & $6.23(0.29)$ & $50.5(5.5)$ \\
\hline 9.00 & 5.66 & 50.2 & 0.250 & $1.93(0.03)$ & $14.63(1.03)$ & $7.70(0.54)$ & $52.9(9.0)$ \\
\hline 15.00 & 9.4 & 53.0 & 0.250 & $1.33(0.02)$ & $13.64(2.19)$ & $10.26(1.66)$ & $50.6(22.1)$ \\
\hline
\end{tabular}

- Values in parentheses are $95 \%$ confidence interval ; uncertainties shown in parentheses are based on maximum crrors equal to three population standard deviations and assume maximum errors of (a) $\pm 0.01^{\prime \prime}$ mechanical measuring error plus $1 \%$ of signal for each phase selective signal, (b) $\pm 0.2^{\circ}$ for the measured phase angle, and (c) $\pm 1 \%$ of full scale in setting the lock-in gain for the voltage follower output. Subscript $s$ indicates value at ac summit potential. Phase angles, $\phi$, are in degres relative to working electrode ac voltage.

+ Phase angle at $d c$ polarographic $E_{1 / 2}$.

$\downarrow \Delta E_{m}$ is the working electrode $a c$ modulation potential at the ac summit potential, $E_{s}$. The rms value would be $0.707 \Delta E_{w r}$.

$\$$ Phase angle at the ac polarographic summit potential. 


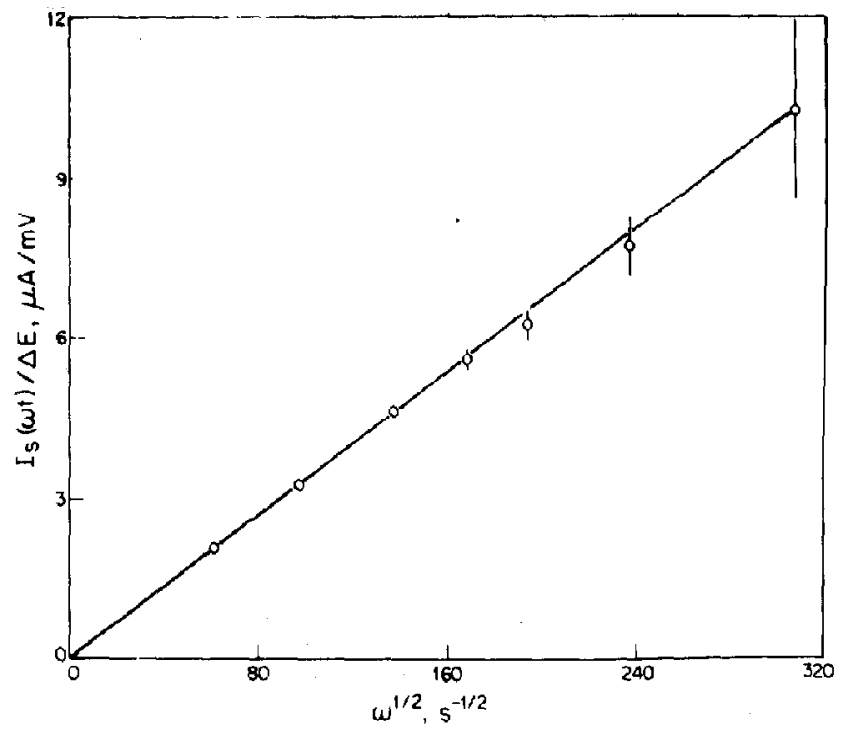

Fig. 17. Variation of ac polarographic faradaic summit current, $I_{\text {, }}(\omega t)$, with frequency, $\omega$ in radians $/ s$, for $1.59 \mathrm{mM} \mathrm{Fe}(\mathrm{III})$ in $1 \mathrm{M} \mathrm{K}_{2} \mathrm{C}_{2} \mathrm{O}_{4}$; other conditions are as for Fig. 15. Uncertainty bars represent $95 \%$ confidence interval assuming three population standard deviations equal to maximum error related to maximum experimental errors of (a) $0.01^{n}$ mechanical measurenent error plus $1 \%$ of signal on all current readouts, (b) $1 \%$ error in peak ac modulation voltage, and (c) $0.2^{\circ}$ error in lock-in phase adjustment.

raphy, the Wavetek 112 sine wave was used as both a reference signal to the lock-in and the $a c$ modulation voltage source for the potentiostat. For noise-free response, the lock-in signal input frequency trim was adjusted for maximum response to the potentiostat's current amplifier output at one of the Fe(III) secondharmonic curtent peak potentials. This procedure gave frequency agreement between fundamental and second-harmonic signals, eg, 1500 and $3000 \mathrm{~Hz}$ within $0.3 \%$. The lock-in phase setting was adjusted for minimum response in the quadrature mode to the current amplifier output, using an applied $d c$ potential negative of the second harmonic peaks.

Qualitative and quantitative interpretation of the second-barmonic ac data for Fe(III) (Fig. 15C) necessitates correction of the raw data because of lock-in amplifier bandpass and the relative magnitudes of fundamental and second-harmonic signals. At $d c$ potentials positive and negative of the Fe(III) ac peaks, the lock-in passed ca $0.8 \%$ of the $1500-\mathrm{Hz}$ ac current while tuned to $3000 \mathrm{~Hz}$, which is less by a factor of ten than the lock-in specifications; however, at $-0.200 \mathrm{~V}$, $0.8 \%$ of the fundamental signal represents $145 \%$ of the observed second-harmonic; the corresponding value at $-0.275 \mathrm{~V}$ is $53 \%$. Since the passed fundamental vectorially adds to the true second-harmonic signal and since the two true second-harmonic peaks are $c a$ $180^{\circ}$ out of phase with each other, while the fundamental signal shows a relatively constant phase, one observed second-harmonic peak will be greatly depressed relative to the other. At $-0.200 \mathrm{~V}$ and $-0.275 \mathrm{~V}$ (within $\pm 0.010 \mathrm{~V}$ of the observed second-harmonic peak potentials), $0.8 \%$ of the fundamental signal was vectorially subtracted from the observed secondharmonic signal to obtain the true second-harmonic current; the corrected signals were $0.245 \mu \mathrm{A}$ and
$0.248 \mu \mathrm{A}$, respectively, compared to observed values of 0.112 and $0.337 \mu \mathrm{A}$.

\section{EYALUATION OF POTENTIOSTAT}

The potentiostat's response range is far wider than that normally eaployed; however, very rapid perturbation provides qualitative, semiquantitative, and, in many cases, quantitative kinetic information, not obtainable by slower technics. Use of a Faradaic cage should result in considerably improved data precision.

\section{Cyclic voltammetry}

There was no detectable instrumental response degradation at the maximum scan rate, $4000 \mathrm{~V} / \mathrm{s}$. Because of stability problems associated with large amounts of ir compensation voltage, low resistance electrodes, eg, non-capillary type electrodes, should be used when possible. Problems have been encountered with use of a Pt-contact hmde for organic systems [13], but, where applicable, this type of electrode, which generally has only 1 to $2 \Omega$ resistance, should be employed.

\section{Potential-step chronoamperometry}

Data acquisition in the presence of a significant capacitive current can be treacherous; the potentiostat-cell configuration should be carefully ordered for minimal RC time constants within the stable range. Use of a low resistance electrode is strongly advised; however, even for the dme, data acquisition starting at $100 \mu$ s permits the study of rapid kinetics.

\section{Pulse polarography}

The potentiostat's observed capability for adsorption studies is impressive. Because the technic's 
sensitivity for adsorption-controlled currents literally decreases exponentially with discharge time after pulse application, whereas the relative contribution of diffusion-controlled current (essentially noise for this type of study) increases with discharge time, the potentiostat's ability to operate at discharge times at least as short as $3 \mathrm{~ms}$-over an order-of-magnitude less than commercial instruments - permits study of weak adsorption. Since the double layer can be charged in less than $200 \mu s[13]$, submillisecond discharge times can be employed, thereby increasing the sensitivity and applicability of the technic even further.

\section{$A C$ polarography}

Phase-selective ac polarography at frequencies to $15 \mathrm{kHz}$ is useful in studies of rapid kinetics; however, since a Faradaic peak is regenerated from a flat signal or negative peak ( $c f$ Fig. $15 \mathrm{~B}$ for $15 \mathrm{kHz}$ ) considerable care in data analysis is required. Phase angle uncertainties at large frequencies ( $c$ Table 2) permit only qualitative or semiquantitative kinetic information without calibrating all instruments to far better than $1 \%$ in terms of both accuracy of full scale response and response linearity.

For second-harmonic ac polarography, electronic rejection of the fundamental harmonic is vitally important, since the latter may be over one hundred times the former. Smith and Reinmuth[14] recommend two Twin-T filter stages as the best method for fundamental harmonic rejection; Smith [15] has discussed the frequency stability requirements for both the lock-in amplifier and the cell ac modulation voltage when using Twin-T filters. A 2-Hz bandpass can be achieved with a single stage Twin-T filter tuned to $1000 \mathrm{~Hz}$.

Although use of $i r$ compensation to eliminate phase shifts and voltage losses seems reasonable, perfect ir compensation is difficult or impossible to achieve; under such circumstances, data analysis becomes difficult. Further, the lock-in phase adjustment procedure becomes more difficult because of the timedependent applied voltage phase, so that a quadrature mode null for the voltage follower output is obtained at only one moment in the drop-life; however, this null does not yield a $d m e$ interphase voltage at $0^{\circ}$. If ir compensation is employed, the current amplifier output $0^{\circ}$ signal must be nulled using a purely capacitative $a c$ current. If perfect ir compensation has not been achieved, a null signal is observed at only one moment in the drop-life, and the ir compensation and phase angle are sequentially adjusted until perfect compensation and phasing is achieved. The procedure is obviously complex and probably involves more pitfalls than use of the method without ir compensation.

\section{Circuit modifications}

For special applications, minor circuit alteration may be necessary. Since circuit alteration is most easily done when the instrument is built, consideration of possible special purposes should be made during initial instrument design.

1. Rapid linear scan voltammetry. The citcuitry in Fig. 1 for the linear ramp generator permits a maximum scan rate of $1.5 \mathrm{~V} / \mathrm{s}$. Two methods can be used to increase the maximum scan rate: (a) increase the fraction of total resistance between switch $\mathrm{S4}$ and ground constituted by $P 2$, eg, if $P 2$ is changed to $30 \mathrm{k} \Omega$, then the maximum scan rate is $2.4 \mathrm{~V} / \mathrm{s}$; or (b) change the integrator RC time-constant ( $5 \mu \mathrm{F} \times 1$ M in Fig. 1) by decreasing the capacitance in the feedback loop of $\mathrm{OA} 4$, eg, if the capacitance is decreased from $5 \mu \mathrm{F}$ to $0.5 \mu \mathrm{F}$, the maximum scan rate is $15 \mathrm{~V} / \mathrm{s}$. The latter technic is preferable, since various capacitors can be placed on a switch in the OA 4 feedback loop, permitting a choice of scan rate ranges; since a fuxed, large scan rate range gives poor sensitivity in setting slow scan rates, $e g$, for $d c$ polarography, either a single small capacitance or a value of $\mathbf{P} 2$ which is large is not advisable.

2. Non-aqueous solutions. For non-aqueous solutions, initial potentials more negative than the $-2.1 \mathrm{~V}$ a vailable may be desired. The available initial potential range can be increased by increasing the fraction of resistance between S1 and ground constituted by $P 1, e g$, if $P 1$ is $3 k \Omega$, then initial potentials of $-2.8 \mathrm{~V}$ are achievable.

Acknowledgement - The authors thank the National Science Foundation, which helped support the work described.

\section{REFERENCES}

1. M. von Stackelberg and H. Freyhold, Z. Elektrochem. 46, $120(1940)$.

2. J. J. Lingane, Chem. Rev. 29, 1 (1941).

3. J.E. B. Randles and K. W. Somerton, Trans. Faraday Soc. 48, 937 (1952)

4. R. deLeeuwe, M. Sluyters-Rehbach and J. H. Sluyters, Electrochim. Acta, 14, 1183 (1969).

5. J. J. Lingane, J. Am. chem. Soc. 68, 2448 (1946).

6. L. Meites, Analyt. Chem. 2il, 895 (1948).

7. M. L. Olmstead, R. G. Hamilton and R. S. Nicholson, Analyt. Chem. 41, 260 (1969).

8. M. A. Jensen, Ph.D. Thesis, University of Michigan, Ann Arbor, Michigan (1977).

9. T. E. Cummings and J.A. Cox, J. electroanal. Chem. 60, 245 (1975).

10. G. S. Alberts and I. Shain, Analyt. Chem. 35, 1859 (1963)

11. W. M. Schwarz and I. Shain, J. phys. Chem. 69, 30 (1965).

12. M. L. Olmstead and R. S. Nicholson, Analyt. Chem. 41, 851 (1969).

13. M. A. Jensen, T. E. Cummings and P. J. Elving, Bioelectrochem. Bioenergetics 4, 447 (1977).

14. D. E. Smith and W. H. Reinmuth, Analyt. Chem. 33, 482 (1961).

15. D. E. Smith, Analyt. Chem. 35, 1811 (1963). 